\title{
Promoción de escuelas inclusivas en contextos migratorios rurales. Análisis desde el enfoque territorial del desarrollo
}

\author{
Promotion of inclusive schools in rural migrant contexts. \\ Analysis from the territorial approach to development
}

\author{
Alejandro Rosendo Chávez ${ }^{a}$, Alejandro Villalobos Martínez, \\ Lucía Fuentes Hernández. \\ ${ }^{a}$ Universidad Autónoma del Estado de México. \\ arc_1222@hotmail.com \\ ${ }^{b}$ Universidad Católica del Maule, Chile. \\ avillalobos@ucm.cl
}

${ }^{c}$ Facultad de Humanidades, Universidad Autónoma del Estado de México. lfuentesmc04@gmail.com

\begin{abstract}
RESUMEN
El presente estudio tiene como propósito analizar cómo, a partir de la dimensión territorial, es posible proponer un sistema escolar inclusivo en contextos migratorios diversos. Para tal efecto se discute en torno a elementos teóricos y desde un enfoque territorial, las estrategias de intervención para que los diferentes niveles de gobierno tengan participación en el fortalecimiento de las estancias y espacios de educación pública ante un contexto de recepción de migrantes internacionales.

Así, desde el enfoque territorial, la educación se presenta como puente y motor de aspiraciones para el desarrollo de las comunidades rurales, siendo necesario profundizar en los mecanismos educativos en los territorios que tienen una importante movilidad de personas mediante la migración. En su conjunto, los resultados sugieren que las políticas públicas, al adoptar el enfoque territorial para el desarrollo, están dirigidas no solo al individuo (escolaridad y activos), sino también al territorio desde el cual los sujetos son actores y agentes del desarrollo; es en este sentido que consideramos que los territorios se configuran y transforman de diferentes maneras mediante la migración, por ello, a través del análisis desde lo territorial, es posible proponer una educación inclusiva para personas migrantes. Para tales propósitos nos interesa abordar ¿de qué modo el enfoque territorial del desarrollo rural puede contribuir al desarrollo de escuelas inclusivas en territorios migrantes?, interrogante que buscamos dilucidar.

Palabras claves: Enfoque Territorial del Desarrollo Rural, Educación inclusiva, Interculturalidad, Territorios migratorios.
\end{abstract}

\footnotetext{
ABSTRACT

The purpose of this study is to analyze how through the promotion of the territories favors the development of inclusive migrant schools, for this purpose they are discussed around theoretical and referential elements that affect the development of an inclusive education considering the migratory processes developed in Chile, but that have the territory as a common articulating axis in the Latin American context. The migratory processes throughout Latin America have been present since its inception, it is interesting to explore how this phenomenon constitutes an important source of interculturality configuration that should be addressed by the school system facilitating and contributing to the development of more inclusive schools. Another aspect to address is how the adaptation and preparation of the territories can favor recent migratory processes, transforming the different actors of the school system into responsible for installing real and effective policies of inclusion. Thus, the binomial education-territory is presented as a bridge and engine of aspirations for the development of rural communities
} 
with migratory characteristics, being necessary to deepen the understanding of the educational mechanisms that make some territories have a better development than others. As a whole, the results suggest that policies should invest both in individuals (schooling and assets), and in territories (public goods, promotion of productive diversification, etc.) so that migratory territories can deploy their potential and achieve development and inclusion. For such purposes we are interested in addressing questions such as: how does the territory contribute to the development of inclusive schools? Is it possible to prepare the territories to establish inclusive public policies? questions that we seek to elucidate.

Key words: Territory, Education, Interculturality, Inclusion, Territories of Migration.

\section{INTRODUCCIÓN}

La migración y el desplazamiento son dos grandes temas prioritarios en la agenda que todo Estado debe abordar para alcanzar los Objetivos de Desarrollo Sostenible (ODS), incluyendo el objetivo de "Garantizar una educación inclusiva, equitativa y de calidad y promover oportunidades de aprendizaje durante toda la vida para todos" (UNESCO, 2019, p. xvii). En ese contexto, las transformaciones sociales y demográficas de Chile en las últimas décadas no necesariamente recogen estos grandes objetivos de las Naciones (Jiménez de la Jara, 2014). En una perspectiva histórica, la población que reside a lo largo y ancho del territorio nacional es el resultado del encuentro de los pueblos originarios y los diversos flujos migratorios europeos que se gestan desde el siglo XVI en adelante. Tal proceso generó un sincretismo étnico-cultural que transformó al país en un receptáculo, cuyo patrón sociodemográfico es el propio de una sociedad mestiza.

Cada proceso migratorio sucedido en Chile ha tenido patrones que se diferencian principalmente en el sentido de la migración (inmigración o emigración) y la procedencia de quienes los protagonizan y que dejan en evidencia las trasformaciones y configuraciones territoriales del cono sur de América como receptor de población, flujo que históricamente ha sido dinámico y cambiante (Villalobos, Sanhueza y Norambuena, 2017).

Por otra parte, en el mundo rural latinoamericano se desarrollan diversos procesos que giran en torno a la desigualdad, pobreza, violencias y crisis económicas, lo que ha generado la salida de su población, primero, hacia las ciudades y luego, hacia otros países. El fenómeno migratorio es una realidad que pone en evidencia las desigualdades y las disparidades territoriales para las sociedades en aumento (Manzanal, 2006), generando cambios profundos en los lugares de origen, tránsito y destino, lo cual se refleja en nuevos procesos sociales, económicos, ambientales y culturales que reconstruyen los territorios (Rodríguez y González, 2006), y desde luego, también impactan en el sistema escolar.

En esta investigación, de corte documental, basamos la construcción metodológica en la revisión bibliográfica del enfoque territorial rural, el sistema educativo incluyente y las migraciones; así, ponemos en perspectiva algunas de las dificultades que ha tenido la sociedad chilena reciente para instalar escuelas inclusivas en territorios que no necesariamente estaban preparados para acoger población migrante de América Latina. Esto nos posibilita perfilar algunas aseveraciones relacionadas con las cuestiones territoriales y migratorias y su incidencia en la educación.

Partimos de entender que los diferentes enfoques de desarrollo rural en Latinoamérica han evolucionado a través de los años dejando atrás ciertas limitaciones ante diferentes contrariedades que surgían en el mismo diseño, formulación e implementación de las 
estrategias para el desarrollo. Estos problemas y temáticas pendientes del desarrollo, permitieron trabajar también sobre las desigualdades territoriales del mundo rural que se encuentran vinculadas a un conjunto de interrelaciones de tipo sistémico, histórico y estructural, específicas a la forma de inserción en la economía mundial y desde luego a las estructuras productivas asociadas a ella (OCDE, 2018), por lo tanto, estas desigualdades territoriales forman parte de la dinámica general del desarrollo y deben explicarse entonces en el marco de una perspectiva más global sin dejar de lado lo local (CEPAL, 2015).

En este sentido, Madoery (2005) da una interpretación política del desarrollo en donde lo local representa un punto de encuentro como el ámbito en donde los agentes territoriales adquieren capacidad de fijar el rumbo y de construir desarrollo. El desarrollo local es, por tanto, un proceso territorializado de maduración social (aprendizaje colectivo para el cambio cultural) y construcción política que se despliega en múltiples dimensiones, sin embargo, no siempre el desarrollo tuvo el mismo alcance en los diferentes territorios dado que el nivel de rezago de algunas regiones o territorios se vinculaba a la dinámica del sistema de regiones como un todo.

\section{TERRITORIO RURAL Y DESARROLLO}

Desde fines de la década de 1940 el problema del desarrollo regional en América Latina y el Caribe se concibió desde un punto de vista intrarregional, principalmente a partir del enfoque de cuencas hidrográficas, asimismo, a mediados de los años sesenta, comenzaron a incorporarse enfoques que las analizaban desde una perspectiva interregional. Este punto de vista influyó en la configuración de nuevos esquemas de políticas y marcos institucionales orientados a enfrentar el problema del desarrollo territorial en varios países de América Latina y el Caribe (Riffo, 2013). Más tarde, en la década de los ochenta comienzan a desarrollarse perspectivas que nuevamente podrían ser calificadas de intrarregionales, tales como el desarrollo endógeno, el desarrollo económico local y la competitividad territorial, que pondrán el acento en factores y recursos internos a un territorio como determinantes de su desempeño económico y social, lo que conducirá a la emergencia de nuevos enfoques de políticas de desarrollo territorial que en términos generales se mantiene hasta nuestros días.

A partir de la década de los noventa, las reflexiones territoriales comienzan a vincularse con los problemas asociados a la globalización y la competitividad (Alburquerque, 2007). Carlos de Mattos y Sergio Boisier son pioneros en reflexionar sobre cómo enfrentar las desigualdades en las regiones. De Mattos (1989) plantea que las estrategias deberían privilegiar la acción organizada e impulsada desde y por la propia colectividad a la que se desea beneficiar. En el siglo XXI la globalidad y el proceso de globalización han colocado en primer plano el papel que tiene el territorio en la constitución de las sociedades, un poco más tal vez que el lugar o el espacio. Como señalaba Ulrich Beck (1998) la globalización implica un ensanchamiento del espacio y la creciente densidad de los intercambios internacionales.

En ese momento, a partir de la incorporación de nuevos aportes conceptuales que pusieron énfasis en los potenciales endógenos de los que disponían los territorios que podían ser activados para generar procesos de desarrollo, destaca en particular la capacidad para la construcción social de proyectos políticos por parte de actores sociales y políticos de cada región a nivel local, considerando también las particularidades de cada territorio (Boisier, 1998), lo cual en algún momento fue una limitante. 
Se da entonces la discusión alrededor de la categoría territorio, que por su fortaleza teórico conceptual y práctico instrumental se considera elemento fundamental para construir la propuesta de pensar al enfoque del desarrollo territorial rural como alternativa de desarrollo de los territorios migratorios en donde la educación juega un rol fundamental para tal propósito. El énfasis en esta categoría ayuda a romper con el análisis sectorial para llevarnos hacia lo territorial.

Es por ello que, al pasar por alto el grado de heterogeneidad de los territorios y las sociedades rurales, así como centrarse únicamente en el perfil agrícola de éstos, esta visión dejaba de lado la pluriactividad y el carácter multiactivo de las unidades familiares, misma situación que ocurría con la diversidad cultural y desde luego el fenómeno de la migración (Schjetman y Berdegué, 2004) que indiscutiblemente reconfigura los territorios rurales a través de la movilidad y circulación de las personas, generando nuevas formas de convivencia en un mundo globalizado, pasando por el lenguaje, formas de interactuar, inserción a nuevas culturas y aprendizajes, además del impacto en las personas migrantes como sujetos de derechos al cruzar fronteras no solo político administrativas, sino sociales y culturales en entornos diferentes.

En estos tiempos de globalización, cada sociedad está atravesada por un sistema de redes y relaciones entre lo local y lo global, que están derivando en la desterritorialización de la vida social hacia una nueva forma de territorializar el espacio. En este contexto, las ciencias sociales y los estudios sobre las migraciones en particular enfrentan el desafío de construir marcos de análisis que impliquen pensar el mundo y los fenómenos sociales como componentes de sociedades globalizadas en donde el territorio tenga un papel determinante (Canales, 2015).

En este sentido, el territorio es más que una porción de tierra, concebido como una totalidad y no solo como espacio físico; es el lugar donde suceden las cosas, las relaciones sociales, es el escenario donde se gestan las condiciones para generar desarrollo, para mejorar las condiciones de la población que vive en ese espacio concreto, constituyendo el soporte físico que permite desarrollar y organizar cualquier actividad humana. Por ello tiene una importancia fundamental en el desarrollo el sistema educativo como uno de los pilares de las sociedades, así como en el fomento de la participación a través de las y los actores del territorio.

Según Sabourin (2002), el territorio es utilizado en una perspectiva de desarrollo; es decir, como una variable a ser considerada cuando se quiere algún tipo de intervención sobre el espacio y las poblaciones, este es el caso de la inserción de las personas migrantes en el sistema educativo en territorios receptores de población de diversos orígenes. De ese modo, el enfoque territorial del desarrollo presupone la acción sobre el espacio y el cambio de las relaciones sociales en él existentes.

La conexión territorial a través del fenómeno migratorio, así como las causas y consecuencias de la migración, permiten abrir la discusión de cómo los migrantes interpretan su experiencia migratoria, y cómo a través de sus prácticas discursivas también construyen una identidad territorial y capital social y económico. Para Reyes y López (2012), la puntualización hacia lo territorial no es un tema propio de la posmodernidad, en realidad ha sido recurrente en la teoría social y una materia fundamental de la geografía humana en donde el ámbito educativo no debe quedar fuera, ya que de acuerdo con estos supuestos, la constitución de los sujetos sociales está ligada indisolublemente a un territorio de escala pequeña, que es parte de una configuración más amplia que la dota de significado: 
en esencia, lo social tiene como fundamento la delimitación y el apego a un territorio que, a su vez, es constituido por diversas interacciones en donde la escuela juega un papel muy importante en la apropiación que los sujetos tienen a los territorios.

Sin embargo, existen desigualdades en el acceso a la educación en los diferentes territorios rurales y urbanos de un mismo país, y estas desigualdades han demostrado ser muy difíciles de superar porque contiene la semilla de su propia reproducción: las oportunidades de educación y de empleo, así como el acceso a servicios básicos que no son distribuidas equitativamente, sumando a ello los fenómenos como el de la migración en lugares en donde anteriormente no se tenía una presencia importante de población migrante de diferentes orígenes con diferentes culturas, lenguajes y arraigos (CEPAL, 2015).

Esta situación agrega una disyuntiva más al problema del desarrollo en los territorios rurales, aunado a una cuestión de mayor vulnerabilidad relacionada con sus pares urbanos, contando con menores oportunidades laborales de empleo y de acceso a educación de calidad, y con altas tasas de pobreza, además de una proporción mayor de personas que no se encuentran estudiando ni en un trabajo remunerado (Espejo, 2017).

Aun cuando en años recientes, en los organismos internacionales para el desarrollo e incluso en las disciplinas sociales se ha discutido sobre la organización espacial de las sociedades entorno a los territorios y la territorialidad no ha llegado a permear en los estudios sobre migración y mucho menos se ha buscado la convergencia entre el desarrollo rural territorial y las oportunidades que puede traer la migración a otro contextos, donde el territorio y la educación sean los ejes articuladores de la propuesta de desarrollo.

Mediante la migración se reconfiguran los espacios y en el actual mundo globalizado, a los migrantes internacionales ya no se les considera gente pasiva como antes, gente que se desarraigaba de su país. Hoy se ha demostrado que son personas que reconfiguran los territorios con su constante ir y venir, influyendo en los procesos sociales, culturales y económicos.

Al interior de estos procesos, los migrantes rurales son agentes permanentes de cambio social que inciden directa e indirectamente en las transformaciones territoriales contemporáneas (Herrera y Rosendo, 2016). Asimismo, los migrantes por su doble cultura y pertenencia desempeñan un papel motor en la creación de puentes de cooperación y solidaridad entre territorios (Merlet, Thirion y Garcés, 2006). En la actualidad se sabe que las personas no sólo se trasladan de un lugar de origen a otro de destino, sino que son capaces de circular, de recorrer espacios y apropiarse de ellos, produciendo territorios y participando en el desarrollo de estos (Faret, 2001; Lara, 2010; Baca, 2011).

Los migrantes rurales han tenido de manera progresiva la oportunidad, vía la educación, de un artificio institucional, espacio físico y orden temporal que fabrica el modo de ser del individuo moderno (Cuesta, 2004) pudiendo así aprender la cultura reconocida y valorada socialmente. En el proceso, el sujeto se apropia de conocimientos y disciplina escolares, asimilándose al proyecto educativo.

\section{EDUCACIÓN}

Al remontarnos al sigo XIX, encontramos que las instituciones educativas públicas constituyeron un elemento fundamental para afianzar la república, fueron centros de enseñanza que no se limitaron a operar un simple programa de instrucción, sino que más 
bien asentaron un proyecto nacional (Dubet y Martuccelli, 1998) yendo en ello implícita la formación de sujetos de la razón y del progreso. La escuela fue un instrumento para la construcción de la unidad nacional en estrecho vínculo con el principio cosmopolita de razón (Popkewitz, 2008).

El pensamiento positivista permea de manera importante en el quehacer de la escuela, que asume una labor titánica cuando se responsabiliza de educar a la población infantil, mediante la escolarización de masas (Popkewitz, 2008). El Estado supuso y aún supone que ese conglomerado estaba constituido por individuos educables, capaces de ser encauzados (Cuesta, 2004). Con esto la escuela fungió como normalizadora de los sujetos que están fuera de los cánones sociales, sobre todo por su diferencia de clase, étnica y condición etaria.

En la actualidad, las condiciones se han complejizado a tal grado que los segmentos de la población son unidades de análisis que merecen un tratamiento por separado, de tal manera que en este trabajo se lleva a cabo una somera mención de la educación que tienen las poblaciones de migrantes en Chile.

Se advierte que las escuelas públicas donde están inscritos niños migrantes son instituciones que poseen una historia que marca el rumbo y roles de quienes allí conviven. Por esto, reconocer los proyectos educativos desde sus orígenes permite elucidar la conformación social de las escuelas en ambas naciones, a partir de sus fines y procesos (Franco, 2017).

Los procesos educativos $\mathrm{y}$, de manera específica, los programas diseñados para atender a estudiantes inmigrantes, tienden generalmente a excluirlos y segregarlos por sus diferencias culturales y sociales mientras que el sistema educativo conmina a que se adapten a las prácticas escolares instituidas de manera unívoca y centralizada, cuestión que no permite que su formación cubra sus necesidades y expectativas.

Surge así la preocupación por educar a las personas alejadas del ideal educativo nacional, como es el caso de los inmigrantes recién llegados, de la población en situación de pobreza, de la población indígena que se encuentran alejadas del lenguaje y costumbres que enarbolan los proyectos nacionales, proyectos que a su vez son herencia de clases medias y altas quienes se educan para recibir y acrecentar el legado cultural de su estirpe (Bourdieu y Passeron, 2003).

Se sugiere que la educación en el siglo XXI ha de ser crítica e inclusiva y para que se llegue a producir hay que aceptar que vivimos nuevos y complejos tiempos por lo que se tienen que modificar aspectos como el mismo sistema educativo, sus fundamentos y sus orientaciones, acelerando el modelo de ciudadanía que impera en la actualidad.

Lo anterior para demostrar que el modelo ilustrado ha quedado obsoleto y no es válido para dar respuesta a la concepción de ciudadanía que debe instalarse en todas las sociedades modernas, tal es la ciudadanía universal e intercultural que tome en cuenta las diferencias territoriales e ideológicas, y que además, considere las demandas sociales a partir de una articulación multisectorial en donde converjan diferentes figuras del territorio, organizaciones sociales, universidades, gobiernos e incluso organismos de cooperación internacional.

El rol de la educación en la comprensión del fenómeno migrante resulta fundamental para cambiar interpretaciones erradas y llenas de prejuicio sobre los extranjeros, como visualizar la valoración de los aportes que hacen al país, no solo desde la perspectiva económica, cultural y social, sino también desde el reconocimiento a nuestro origen, 
y múltiples identidades. Aunque Chile aparece tremendamente valorado como país de acogida, internamente existen datos y cifras que lo perfilan como un país donde la desigualdad cobra más protagonismo del que quisiéramos:

la desigualdad socioeconómica en Chile ha tenido una connotación étnica y racial. Las clases altas se configuraron como predominantemente blancas, mientras que mestizos e indígenas ocuparon un grado más bajo en la jerarquía social, y negros y mulatos uno aún más bajo. Incluso hoy el aspecto físico es un buen predictor de la clase social en Chile, lo que delata a una sociedad con escasa movilidad social, en la que han primado los prejuicios y la discriminación en el acceso a las oportunidades (PNUD, 2017, p. 34).

Este fenómeno, como bien reconocen las Naciones Unidas, es amplificado cuando enfrentamos los nuevos escenarios migrantes, diversos y complejos y pone de manifiesto los temores y dificultades que como sociedad no hemos superado del todo, debilidades que se asocian a lo desconocido de una sociedad multicultural y multiétnica.

La teoría concuerda en que la multiculturalidad y la interculturalidad son las principales vías para abordar la problemática migrante, indicamos problemática porque aún no entendemos de qué manera el migrante se está incorporando a nuestra sociedad. Stefoni, Stang y Riedemann (2016), han dedicado parte de sus investigaciones, con ayuda de Programa Servicio País, de la Fundación Superación de la Pobreza (FUSUPO), a fundamentar la necesidad de que la educación avance hacia una educación intercultural para concretar una educación que tenga carácter inclusivo. Estos autores se refieren a procesos de inserción social basado en tres enfoques, asimilacionista, multicultural o intercultural. Conscientes de la ardua discusión detrás de cada término, históricamente el asimilacionismo es la forma en que los países de alto ingreso han acogido a los migrantes (UNESCO, 2019, p. xvii). Esto conlleva al que se integra, a convertirse en uno más de 'nosotros', aparecen frases como 'ellos deben adaptarse a nuestras normas y costumbres' quedando con esto claro que el asimilacionismo es la crónica de una muerte anunciada para la cultura del que viene llegando. Lo multicultural asume la existencia de una cultura, sin embargo, esta jerarquiza ubicando a la cultura que recibe como predominante respecto de las 'otras' culturas, con lo que la segregación adquiere forma y sentido. Siendo en Chile la forma más evidente de convivir, se considera la presencia de otras culturas, pero generándose en algunos casos una relación más bien folclorizada de las 'culturas diversas'.

La migración y la educación, interactúan de forma recíproca en el espacio regido por normas, primero los Estados deben reconocer en su legislación y derecho a la población migrante, luego a partir de la educación es que las relaciones culturales comienzan el avance en el proceso de "integración", entender que desde el conocer al otro y ocuparse ya hemos generado nuevo conocimiento por ambas partes. Según el Censo 2017 en Chile la población de migrantes en edad escolar ha ido en creciente aumento, de un 0,9\% (2015) a un $3,2 \%$ (2018). Esto implica un desafío para nuestro sistema escolar, con una creciente demanda por matrículas y con ello la primera barrera burocrática para la inclusión es el hecho que la burocracia estatal determina el o los establecimientos educativos donde los estudiantes migrantes acceden al sistema educacional chileno, principalmente aquellos de dependencia municipal.

Por tanto, lo anterior evidencia que para que exista un real proceso de inclusión de la población migrante, los territorios receptores de población deben abordar las implicancias 
educativas focalizadas en acceso y acompañamiento. Entonces, ¿qué acciones concretas se han realizado en Chile para abordar la demanda de la población migrante? Probablemente, la principal respuesta es que Chile avanzó en asegurar el acceso a la educación para todas y todos, dando pasos para asegurar igualdad y no discriminación, promoviendo la valoración de la diversidad al interior de las comunidades educativas como punto de partida para el enriquecimiento de las prácticas educativas (Instructivo Presidencial $n^{\circ} 5,2015$ ). Sin embargo, la autonomía que poseen los municipios para determinar a qué establecimientos se incorporan los migrantes genera una posibilidad y tendencia a crear espacios educativos segregados, en donde las comunidades migrantes estarían siendo confinadas a educar a sus hijos e hijas no siempre en las escuelas con mejores resultados, siendo esta una de las principales críticas al actual sistema de admisión a las escuelas públicas de Chile, cuestión que facilitaría un nuevo enfoque de segregación (Valenzuela, 2013).

Por otra parte, el marco normativo para garantizar el acceso, permanencia y avance en la trayectoria educativa de estudiantes extranjeros señala a la Declaración Universal de Derechos Humanos y la Convención sobre los Derechos del Niño(a) como base declarativa del país, sumándose la Convención Internacional sobre la Protección de los Derechos de Todos los Trabajadores Migratorios y sus Familias, aprobada por la Asamblea General de las Naciones Unidad en 1990 y ratificada por el Estado de Chile en 2005. Esta convención promueve el trato igualitario en el ejercicio y goce de derechos civiles y políticos, económicos, sociales y culturales a los trabajadores migratorios y sus familiares en general.

En el marco internacional existen diversas convenciones ratificadas por Chile donde se profundiza en la promoción de derechos para las personas en situación migratoria. A nivel regional existen acuerdos multilaterales que se encuentran vigentes referidos a seguridad, protección social, entre otros. Uno de ellos es el Convenio Andrés Bello (CBA), que es particularmente importante para el sistema educativo, vigente desde $1990 \mathrm{y}$ tiene por objetivo fortalecer los procesos de integración, la configuración y desarrollo de un espacio cultural común iberoamericano, garantizando el reconocimiento de los estudios realizados en cualquiera de los países miembros. Lamentablemente, Haití, un país que aumentó notoriamente su flujo de migrantes hacia Chile, no está suscrito al CBA. Sin embargo, el año 2017 Chile y Haití firmaron un acuerdo para la equiparación de estudios, como una forma de garantizar los derechos fundamentales de las personas migrantes.

Por otra parte, el marco legal basado en la Constitución Política vigente no contempla disposiciones específicas para personas migrantes, no obstante, sí garantiza el derecho a la educación a todas las personas que residen en nuestro territorio, por tanto, debe hacerse cargo de la educación de quienes son inmigrantes (Artículo 19 n¹0, Constitución de 1980), este mandato legal implícitamente estaría instalando la necesidad de incorporar a comunidades culturales diversas avecindadas en Chile.

En el mismo sentido y complementariamente, el Instructivo Presidencial $\mathrm{N}^{\circ} 5$ emitido el año 2015, proporciona lineamientos e instrucciones para una política nacional migratoria. Específicamente en el ámbito de la educación mandata que se debe garantizar a niñas, niños y adolescentes de familias migrantes el acceso, permanencia y progreso de su trayectoria educativa en igualdad de condiciones con independencia de su nacionalidad, origen o situación migratoria, reconociendo además el valor de su cultura y propiciando un trato inclusivo (Artículo n⿳05 del Instructivo Presidencial No5).

Otro referente fundamental para la inclusión de migrantes es la normativa legal educacional. De este modo, la ley general de educación reconoce en el Artículo $3^{\circ}$ Inciso 
1, el principio de la interculturalidad, en el que se establece que el sistema debe reconocer y valorar al individuo en su especificidad cultural y de origen, considerando su lengua, cosmovisión e historia (Ley N²0.370/209).

Evidentemente, pese a los esfuerzos normativos, la sola coexistencia de la diversidad no garantiza que una comunidad heterogénea sea dialogante e inclusiva, más bien, en el espíritu de la norma, solo estaríamos fomentando y garantizando la multiculturalidad.

Por último, los niños hijos de migrantes están siendo vistos, peligrosamente, sólo como una oportunidad para mantener y fortalecer el sistema basado en el volumen de matrículas. Hoy los niños hijos de migrantes en edad escolar, han detenido la baja sostenida de matrículas del sistema público, para esto disponen de un Identificador Provisorio Escolar (IPE), en caso de no contar con cédula de identidad, acto que además les permite acceder a una matrícula definitiva con todos los derechos que eso implica, independiente de su situación migratoria. Actualmente, el sistema de control migratorio se encuentra regulado especialmente para los niños, otorgándoles incluso una visa temporaria (NNA) para niños y niñas menores de 18 años, independiente de la situación migratoria de los padres, todo lo anterior según modificaciones al SIGE 2017 que incorpora los Ordinarios No 894 y No 329.

\section{GOBERNANZA Y GESTIÓN EDUCATIVA PARA LA INCLUSIÓN}

La capacidad para mejorar de una unidad educativa depende, de forma significativa, de líderes que contribuyan activamente a dinamizar, apoyar y animar a que su escuela aprenda a desarrollarse, haciendo las cosas progresivamente mejor (Bolívar, López y Murillo, 2013). A su vez, quien comienza una carrera educacional habitualmente llega con una visión utópica de cómo hacer las cosas, con entusiasmo y alta motivación. Sin embargo, con el paso de los años la experiencia alcanzada, permite dimensionar al sistema educacional en toda su magnitud y complejidad, permitiendo especialmente apreciar que se requieren de potentes factores que motiven el deseo de instalar cambios e innovación, los que no siempre tendrán una contraparte eficiente y eficaz para el logro de fines y propósitos de instalar mejoramiento al interior de las aulas.

Estos deseos de innovación y cambios necesariamente implican ser consciente de la importancia de la educación en la sociedad, lo cual involucra albergar a la escuela como eje de una responsabilidad social individual y colectiva, que trascienda de un perfil académico y administrativo en donde los actores involucrados tengan agencia y participen en las tomas de decisiones y propuestas escolares considerando también los cambios y transformaciones recientes como la inserción de estudiantes migrantes en las escuelas.

Es fundamental que la persona que asume dicha tarea comprenda su rol y conozca el impacto que puede generar, particularmente directores, jefes de unidad técnica, orientadores, y quienes conforman los equipos directivos de los establecimientos dado que son ellos quienes deben facilitar la innovación educativa y transformarse en agentes de cambio. Sin embargo, el sinnúmero de requerimientos administrativos y de toda índole que los equipos directivos actualmente cumplen, desvirtúan su trabajo atentando directamente a la calidad de educativa, complejizando asumir nuevos desafíos (Barrera, 2017).

Asimismo, y como está planteado desde un enfoque territorial en donde los sujetos del territorio son agentes de cambio, se debe asumir la consecuencia de tomar conciencia de las situaciones que es necesario dar prioridad para atender y resolver las dificultades. 
Claramente, a luz de las diferentes perspectivas de interculturalidad y de procesos migratorios, los actuales contextos histórico-culturales, legales, sociales y educacionales requieren que existan liderazgos educativos que a través de la innovación generen cambios que reviertan la situación intercultural de los establecimientos educacionales de la región y el país.

Para lograr la eficiencia en la gestión de estos y otros cambios, no solo se debe estar informado de los factores que inciden en una crisis, sino que también se debe contar con una actitud que se reconoce por sobre los demás, el liderazgo, esa energía la que ayudará a encaminar la misión propuesta. Hoy claramente podríamos reconocer que el sistema está bordeando una crisis que se agudizará si no es capaz de potenciar que sus propios equipos directivos diseñen acciones para transformar a sus establecimientos en instancias de acogida y facilitadores de la interculturalidad.

De este modo se va propiciando y haciéndose cargo de la inclusión educativa de manera eficiente y eficaz, promoviendo interacciones fronterizas que aseguren un aprendizaje que supere las acciones de la sala clase para constituir comunidades de prácticas y de generación de conocimiento (Harris, 2012). El problema que se presenta es que en América Latina, de acuerdo al último informe PISA, los equipos directivos no acostumbran o promueven poco las prácticas de enseñanza basadas en investigaciones educativas recientes, situación que se advierte de forma parecida en diferentes países de la OCDE (Vaillant, 2019), de tal modo que la revisión de estudios e investigaciones que influyan en los cambios e innovaciones es un factor a considerar a la hora de pensar en las condiciones favorables para la puesta en marcha de transformaciones proclives a la inclusión de comunidades migrantes en el país. Podríamos preguntarnos por qué la investigación no es un insumo frecuente a la hora de mejorar las prácticas de enseñanza. Un elemento explicativo podría ser el escaso tiempo que los equipos directivos disponen para su propia actualización y acceso a investigaciones recientes.

La complejidad de este sistema educativo escolar nos invita a entender cómo crecen y evolucionan las organizaciones y cómo es posible plantear cambios para lograr el éxito. El sistema escolar chileno se encuentra haciendo frente a factores desafiantes que no solo ponen en riesgo el sistema, sino que especialmente lo alertan de que la interculturalidad y la diversidad son fenómenos presentes y que no solo las escuelas, a partir de sus equipos de gestión, deben asumir, sino que también corresponde a los diversos actores del territorio participar y promover a través de la organización, la instalación de cambios sociales desde la educación. El desafío está en responder ¿cómo lograr identificar los factores de riesgo en este sistema?, ¿cómo se abordan dichos riesgos desde la sociedad civil en los territorios? y ¿qué sucede en el actual ambiente educacional nacional?

Una de las alternativas eficientes que visualizamos frente a los factores de riesgo del sistema escolar, es a través de la instalación de liderazgos exitosos basados en la conformación de comunidades de aprendizajes activas en la que participan todos los actores, contribuyendo a formar escuelas más participativas y democráticas. Se considera entonces como liderazgo exitoso a la contribución que desde los equipos de gestión se impulsan para definir: la visión, valores y misión de la escuela, mejorar las condiciones de enseñanza y de aprendizaje, rediseñar y enriquecer el plan de estudios, mejorar la calidad de la formación de los docentes, diseñar proyectos educativos dentro de la comunidad escolar, enfatizar en valores comunes (Day y Sammons, 2013).

Desde ese punto de vista la ideología, visión y misión que sustentan al equipo de gestión son clave para promover aprendizajes interculturales comunitarios (Kanold, 2011), situación que es altamente beneficiosa si es vista como prioritaria al interior de los 
establecimientos, dichos cambios fortalecen los niveles de participación en las definiciones de inclusión a los nuevos actores, en la medida que la comunidad escolar asiste y participa con programas de acogida y recepción de migrantes.

Observar y analizar diferentes organizaciones educacionales y, por otra parte, las organizaciones menos efectivas en el desarrollo de acciones de inclusión, ya que aquellas permiten ver cómo se encaminan al fracaso debido al desconocimiento de su propia historia escolar y en algunos casos las historias de otros, tomando lecciones del pasado. Pretender que siempre veremos el mismo programa de televisión con un mismo formato y entusiasmo es arrogante, pero hoy tanto la televisión como las redes sociales entienden que deben enfrentar crisis permanentemente, por mucho que la fórmula inicial sea exitosa esto jamás será eterno, entonces cambio e innovación es la tarea permanente, y hasta el momento las escuelas no tienen claridad o soportes que fundamenten cómo instalar la inclusión de comunidades migrantes e interculturales en sus propios núcleos de desarrollo, solo especulan con acciones poco planificadas desde la propia escuela, más bien son totalmente reactivas a los instructivos escolares, dando cuenta de la rigidez como forma, opuesta a la apertura como cultura institucional.

Al respecto, Greiner (1972) señala que las organizaciones educativas se mueven por cinco etapas de desarrollo, cada una de ellas finaliza con una crisis que es superada en la etapa siguiente. Las instituciones en la medida que van creciendo se van complejizando aún más, con periodos de evolución y revolución, crecen con éxitos y fracasos, siendo estos últimos la señal de una decadencia y estancamiento en ellas. Juega aquí un rol fundamental la tarea de un líder que dirija con agudeza, perspicacia y visión de cambio para encaminar a la institución a nuevos tiempos, como también se hace fundamental que quienes lideren escuelas, sean personas capaces de realizar una lectura a los procesos de cambios que afectan no solo a la institución, sino al contexto global en el que se inserta, es decir la escuela no es un estanco separado de la realidad global, nacional, regional o local, tal como hoy podemos apreciar respecto a los procesos migratorios recientes que impactan a la sociedad chilena, cuyos efectos se verán en las escuelas.

Desde esa mirada de la gestión y la gobernanza escolar, debemos reconocer que hoy, se demanda del sistema educativo una gestión más efectiva en lo que a educación inclusiva se refiere. Así, por ejemplo, trabajar para fomentar y difundir la diversidad cultural de los territorios en contextos migratorios, y también de los pueblos originarios, es una tarea que sigue siendo un desafío. Probablemente, las herramientas con las que el sistema escolar puede contar para acoger al migrante deban retomar elementos del contexto de las escuelas y de los estudiantes migrantes en donde estos estudiantes tengan también participación en el sistema educativo desde diferentes visiones, para de esta forma enriquecer las aulas de otras culturas y que desde luego tendrá un impacto importante en las escuelas.

Al mismo tiempo, el Ministerio de Educación realiza sugerencias de acciones para instituciones escolares que llegaran a tener matrícula extranjera, uno de esos es el texto: "Orientaciones Técnicas para la Inclusión Educativa de Estudiantes Extranjero", publicado en diciembre del 2017. En el documento se puede apreciar una clara orientación en lo referido al trabajo con los estudiantes extranjeros, sobre todo en el cuarto capítulo donde se indican "sugerencias de gestión" para trabajar con los estudiantes extranjeros, considerando elementos normativos, conocimiento de los estudiantes y participación de las familias, no olvidemos que es el espacio escolar en donde las familias migrantes y sus hijos inician los primeros nexos con la sociedad de acogida. 
Una comunidad educativa con vocación intercultural se construye a partir de la riqueza de identidades y culturas de quienes forman parte de esta, y particularmente de los estudiantes (MINEDUC, 2017). Lamentablemente, todo lo anterior se puede interpretar como medidas circunstanciales; si la escuela no presenta matrícula de niños extranjeros, ésta no verá la necesidad de revisar esas sugerencias y mucho menos hacer énfasis en la educación intercultural y será un tema alejado de la comunidad al no ser éste una necesidad.

La diversidad cultural no es algo nuevo en Chile, como tampoco en nuestro sistema educacional, pero la llegada de migrantes, y este nuevo perfil descrito en los párrafos anteriores, nos empuja a hacer una revisión de las percepciones que nuestra sociedad tiene, preconcepciones y estereotipos que aún conviven al interior de las comunidades educativas planteando desafíos en las prácticas de gestión directiva y pedagógica, para luego avanzar en la construcción de una propuesta educativa con enfoque intercultural.

Entonces, la posibilidad de ser una escuela efectiva, entendiendo la inclusión, no sólo circunstancialmente sino operativamente, depende de diferentes factores y de la participación de diferentes actores y niveles. Por un lado, a partir del reconocimiento de la diversidad en las escuelas y del fenómeno cambiante de éstas mediante la migración como un fenómeno actual y en auge en el país, en segundo término, de la voluntad desde las instituciones para implementar un nuevo modelo de educación inclusiva; y por último y no menos importante, la participación de los actores en la toma de decisiones y estrategias para facilitar el proceso.

Las escuelas necesitan establecer conexiones de carácter consciente y constructivo que traspase a los tiempos que vive, dado que no puede cerrar sus puertas y dejar los problemas del mundo fuera (Hargreaves y Fullan, 2012). La conformación familiar, la pobreza, los materiales obsoletos, las dimensiones interculturales, entre otros, son factores que hoy están presentes ampliando las responsabilidades de los docentes.

Los cambios estructurales son necesarios, pero no suficientes para provocar un cambio significativo, es decir, entender que se tiene un problema e identificar qué cambios se deben hacer no es equivalente a saber cómo provocar los cambios. Además, la solución más efectiva no implica dejar que los usuarios individuales hagan sus propias elecciones en contextos permisivos (Fullan, 2002).

A través del Marco para la buena dirección y Liderazgo escolar, el Ministerio de Educación declara la preocupación por la educación justa, en una de las prácticas que componen la dimensión de gestión de la convivencia y participación de la comunidad escolar señala lo siguiente: "Desarrollan e implementan una política que asegura una cultura inclusiva y las condiciones para que las personas se traten de manera equitativa, justa, con dignidad y respeto, resguardando los derechos y deberes de la comunidad escolar" (MBDLE-MINEDUC, 2015). Esta declaración compromete de manera directa a la dirección de las escuelas para considerar una educación inclusiva, la que como ya sabemos atiende parcialmente, sin embargo, el conocimiento de ellos respecto de la interculturalidad carece de una actualización apropiada.

El Servicio Jesuita Migrante, en su programa "Migración y Escuela", consideró experiencias de cinco establecimientos educacionales, dos de Santiago, dos de Antofagasta y uno de Arica. A la luz de ese trabajo se concluye, que el fenómeno migratorio, visto desde las escuelas, emplaza tanto al funcionamiento y dinámicas de las instituciones chilenas en general, como el sentido común que ha forjado la sociedad local de sí misma, incidiendo en las percepciones de los estudiantes tanto chilenos como extranjeros. Igualmente, al conocer 
la metodología de trabajo implícitamente se observa que si bien es cierto las escuelas manifiestan elementos comunes frente a la necesidad, aun así, existen diferencias, lo que las hace auténticas en la conformación de sus planes de mejora e implementación a la comunidad extranjera (SJM, 2017).

En España y en países de Latinoamérica, ya han trabajado ciertas experiencias en multiculturalidad e interculturalidad en las escuelas, centradas fundamentalmente en el fortalecimiento de las lenguas indígenas (Salazar, 2009), siendo claramente el trabajo de las lenguas un aporte y un antecedente a considerar.

En Chile, tenemos acciones que podemos mostrar. Desde quienes dirigen nuestras acciones educativas sólo se han entregado sugerencias. Al hacer un recorrido por lo que el ministerio propone para poder abordar la educación de carácter inclusivo, sólo es posible encontrar manuales referidos al trato de la cultura de nuestros pueblos originarios.

La inclusión, como objetivo de cohesión social, convivencia democrática y el fomento de una cultura de paz, es sin duda a lo que debemos apuntar en nuestras acciones. Es en ese sentido que las escuelas que hoy se consideran inclusivas, declaran componentes que favorecen el dialogo intercultural, y fortalecen la construcción de un entramado social ciudadano y participativo (Salazar, 2009).

Entonces es necesario asumir que se necesita una mejora educativa, "para que el trayecto de mejora del sistema escolar pueda ser sostenible en el largo plazo, las mejoras deben estar integradas en el tejido del sistema pedagógico" (McKensey, 2010, p. 11). No es suficiente hablar de sugerencias pedagógicas o administrativas, así solo seguiremos dando vueltas en círculos, y la idea de inclusión versus exclusión será sólo una romántica idea con el que nadie se compromete y que las futuras generaciones, si tienen suerte, lograrán entender estando en otros territorios donde la interculturalidad, multiculturalidad o transculturalidad será un elemento que sólo suma a la experiencia de sus vidas.

\section{DESARROLLO RURAL Y EDUCACIÓN EN TERRITORIOS MIGRANTES}

Los migrantes rurales, con sus condiciones en contra, tienen potencialidades ya que tienen mayor proximidad a las sociedades desarrolladas en donde se vive mejor, aunado con la ayuda de las redes sociales que han tejido a través del tiempo y con una cultura de la información y el uso de nuevas tecnologías, generando mayor capacidad de innovación y movimiento entre lo urbano y lo rural y aún entre países.

La educación rural atiende particularmente a población más vulnerable o más bien vulnerada, a infantes y jóvenes cuyos padres tienen un ingreso promedio mucho menor que sus pares urbanos (dos veces más bajo, según la Agencia de Calidad de la Educación) y menor escolaridad que sus pares urbanos y aún en sociedades fragmentadas por la migración de una parte de su población.

De manera casi determinista existe una gran cantidad de evidencia que ha relacionado los recursos económicos de las familias con los resultados académicos de los estudiantes, esos hijos e hijas, de familias rurales, presentan mayores tasas de deserción escolar, debido a una acumulación histórica y sinérgica de inequidades con las minorías, como los migrantes.

Para que la población rural sobre todo en los territorios de migración pueda desplegar su potencial y contar con oportunidades equivalentes a las de sus pares urbanos, se requiere profundizar los esfuerzos de inclusión y calidad que beneficien al sistema educativo 
en su conjunto, además de ofertas educativas pertinentes a la situación, necesidades y aspiraciones y de acuerdo con el contexto, a las condiciones territoriales.

Si bien actualmente la población rural y aún migrante cuenta con un nivel educacional más avanzado que el de las generaciones previas, como consecuencia de las mayores coberturas educativas en la región de las últimas décadas, las brechas territoriales en educación siguen vigentes, observándose menores tasas de participación y de conclusión educativa en los sectores vulnerables.

Esta condición de rezago en relación con los territorios urbanos es concordante con que los territorios rezagados, es decir aquellos cuyos indicadores sociales han avanzado por debajo de las medias nacionales, tienden a ser zonas rurales, con menor número de habitantes, condiciones que encontramos en los territorios migratorios rurales. Del mismo modo, esta condición de rezago en el caso de Chile se agudiza cuando la migración es de origen latinoamericana, y por tanto se van configurando estigmatizaciones que caracterizan el proceso de instalación de los migrantes tanto en un territorio como en el sistema escolar chileno hasta las segundas y terceras generaciones (Hein, 2012).

\section{CONCLUSIONES}

Se ha de tomar en cuenta al territorio como espacio y campo en el que las acciones, estrategias y trayectorias de los actores buscan que el vector de los movimientos sea ascendente, convirtiéndose de esta forma en una unidad importante para el planeamiento e implementación de las acciones de desarrollo. Así los migrantes son actores de cambio, en búsqueda de mejores condiciones de vida, en el que tratan de que su movimiento sea ascendente. El territorio como eje articulador del desarrollo tiene una influencia importante en las aspiraciones de inclusión de la población migrante.

El factor educativo como puente para cumplir con las aspiraciones de integración y desarrollo, en donde se tenga un modelo educativo que sea incluyente y tome en consideración la cuestión territorial, con un énfasis en los territorios rurales que son históricamente más atrasados sobre todo en territorios donde se tiene emigración e inmigración, lugares que tienen cuestiones muy complejas.

La necesidad de cambiar el modelo de enseñanza y la forma de implementación de las políticas públicas deben ir en concordancia con la aspiración de desarrollo en los territorios rurales y particularmente en los territorios en donde se tiene una gran presencia de migración, que son lugares donde se complejizan las condiciones como seres humanos.

Los procesos migratorios recientes han puesto en entredicho la efectividad de políticas públicas que facilitan la inclusión y la interculturalidad; asimismo resulta relevante observar de qué forma los equipos de gestión de las escuelas y establecimientos educacionales, asumen el liderazgo y el rol transformador que permita superar estigmas y paradigmas que no reconocen la diversidad, entendida esta como la normalidad de las relaciones en el mundo globalizado actual y eje central para la instalación de escuelas más democráticas e inclusivas.

\section{REFERENCIAS BIBLIOGRÁFICAS}

Alburquerque, F. (2007). Desarrollo económico local y distribución del progreso técnico. Una respuesta a las exigencias del ajuste estructural. Cuadernos del ILPES, (43), CEPAL, Naciones 
Unidas, Santiago de Chile.

Baca, N. (2011). Lógicas de circulación y migración femenina del sur mexiquense a Estados Unido. Universidad Nacional Autónoma de México: México.

Barrera, F. (2017). Simplificar Los Requerimientos A Los Directivos Escolares: Una necesidad perentoria para el despliegue del liderazgo educativo a los establecimientos. Informe CEDLE Política Educativa, (pp. 1-19), Santiago de Chile.

Beck, U. (1998). La sociedad del riesgo. Hacia una nueva modernidad. Barcelona: Paidós.

Boiser, S. (1998). Post-scriptum sobre desarrollo regional: modelos reales y modelos mentales. Anales de Geografía de la Universidad Complutense de Madrid, 13-15.

Bolívar, A., López, J. y Murillo, F. J. (2013). Liderazgo en las instituciones educativas. Una revisión de líneas de investigación. Revista Fuentes, (14), 15-60.

Bourdieu, P. y Passeron, J. C. (2003). Los herederos. Los estudiantes y la cultura. Buenos Aires: Siglo XXI.

Canales, A. (2015). E pur si muove, Elementos para una teoría de las migraciones en el capitalismo global. Universidad de Guadalajara: México.

Comisión Económica para América Latina y el Caribe. (2015). Panorama del desarrollo territorial en América Latina y el Caribe, 2015. Pactos para la igualdad territorial. Naciones Unidas, CEPAL, Santiago: Chile.

Cuesta, R. (2004). La escolarización de masas: un sospechoso y feliz consenso transcultural. Cuadernos de Pedagogía (Madrid), (334), abril, 1- 10.

Day, C., \& Sammons, P. (2013). Successful Leadership. Rescatado de: http://cdn.cfbt.com/ /media/ cfbtcorporate/files/research/2013/r-successfulleadership-2013.pdf.

De Mattos, C. (1989). La Descentralización, una nueva panacea para enfrentar el subdesarrollo regional? Revista Paraguaya de Sociología, 26(174), enero-abril.

Dubet, F. y Martuccelli, D. (1998). En la escuela. Sociología de la experiencia escolar. Buenos Aires: Editorial Losada.

Espejo, A. (2017). Inserción laboral de los jóvenes rurales en América Latina. Un breve análisis descriptivo. Grupos de Diálogo Rural, una estrategia de incidencia, Documento $N^{\circ} 225$. Rimisp: Chile.

Faret, L. (2001). The territories of mobility: socio-spatial logic of migrant groups between Mexico and the US. Université Paris VII-SEDET: Paris.

Franco, M. (2017). Sistemas educativos y migración. Una mirada a la educación en Estados Unidos y México. Revista mexicana de investigación educativa, 22(74).

Fullan, M. (2002). El significado del cambio educativo: un cuarto de siglo de aprendizaje. Profesorado. Revista de Currículum y Formación de Profesorado, 6(1-2), 1-14.

Greiner, L. (1972). Crecimiento y evolución de las organizaciones educacionales. Rescatado de: http://www.unimet.edu.ve/wp-content/uploads/sites/3/2014/10/Evoluci\%C3\%B3n-yRevoluci\%C3\%B3n-del-Crecimiento-de-las-Organizaciones.-Lary-Greiner.pdf

Harris, A. (2012). Liderazgo y desarrollo de capacidades en la escuela. Cap. 1. Cruzar fronteras y romper barreras: hacia un Liderazgo distribuido en las escuelas. Santiago: Fundación Chile.

Hargreaves, A. y Fullan, M. (2012). Professional Capital. Teachers College: Columbia University.

Hein, K. (2012). Migración y Transición: Hijos de inmigrantes de origen latinoamericano en su transición de la escuela al trabajo en Chile. Si Somos Americanos, 12(1), 101-126. https://dx.doi. org/10.4067/S0719-09482012000100005.

Herrera, F. y Rosendo, A. (2016). Territorialidad rural y redes de migración de Almoloya de Alquisiras. Un análisis desde la mirada de sus protagonistas. En J. Olvera y N. Baca (coords.), Continuidades y cambios en las migraciones de México a Estados Unidos. Universidad Autónoma del Estado de México-The University of Texas at San Antonio. Toluca, México, 288-309.

Jiménez de la Jara, M. (2014). Inmigrantes en Chile. ¿Nuevo grupo de Presión social de la sociedad civil frente al Estado? En B. Estrada, (Ed.), Inmigración Internacional en Chile. Un tema en Desarrollo, (pp. 162-181). Viña del Mar, Chile. 
Estudios Pedagógicos XLV, N 3: 279-295, 2019

PROMOCIÓN DE ESCUELAS INCLUSIVAS EN CONTEXTOS MIGRATORIOS RURALES. ANÁLISIS DESDE EL ENFOQUE TERRITORIAL DEL DESARROLLO

Kanold, T. (2011). The Five Disciplines of PLC Leaders. Bloomington, In: Solution Tree Press.

Lara, S. (2010), (Coord.). Migraciones de trabajo y movilidad territorial. Editorial Miguel Ángel Porrúa: México.

Madoery, O. (2005). La "primera generación" de políticas locales de desarrollo en Argentina: contexto, características y desafíos”. Material de la Maestría en Desarrollo Económico. UAMUNSaM.

Manzanal, M. (2006). Regiones, territorios e institucionalidad del desarrollo rural. En Mabel Manzanal, Guillermo Neiman y Mario Lattuada (Comps.), Desarrollo rural, organizaciones, instituciones y territorio (pp. 21-50). CICCUS: Argentina.

Mckinsey \& Co. (2010). ¿Cómo se convierte un sistema educativo de bajo desempeño en uno bueno? Sumario ejecutivo en español del informe "How the world's most improved school systems keep getting better".

http://www.mckinsey.com/clientservice/Social_Sector/our_practices/Education/Knowledge_ Highlights/ /media/Reports/.

Merlet, M., Thirion, S. y Garcés, V. (2006). Estado y sociedades civiles, acceso a tierra y desarrollo rural: Reforzar las capacidades para nuevas formas de gobernanza. En Conferencia Internacional sobre Reforma Agraria y el Desarrollo Rural, FAO, Portugal.

Ministerio de Educación. (2015). Marco para la buena dirección y liderazgo escolar. Recuperado de https://liderazgoescolar.mineduc.cl/marco-para-la-buena-direccion-y-el-liderazgo-escolar/.

Ministerio de Educación. (2017). Orientaciones técnicas para la inclusión educativa de estudiantes extranjeros. Recuperado de https://www.mineduc.cl/2017/12/22/orientaciones-la-inclusioneducativa- los-estudiantes-extranjeros/.

Mundaca, P., Fernández, N., y Vicuña, J. (2017). Migración en Chile: un análisis desde el censo 2017. Chile: Servicio Jesuita a Migrantes.

OCDE. (2018). Estudios económicos de la OCDE para Chile 2018. Recuperado de https://www. oecd.org/eco/surveys/Chile-2018-OECD-economic-sruvey-Spanish.pdf.

Popkewitz, T. (2008). Cosmopolitanism and the age of school reform: Science, education, and making society by making the child. New York: Routledge [Edic. cast.: El cosmopolitismo y la era de la reforma escolar. La ciencia, la educación y la construcción de la infancia. Madrid: Ediciones Morata, 2009].

PNUD (2017). Desiguales. Orígenes, cambios y desafíos de la brecha social en Chile. Santiago de Chile: Programa de las Naciones Unidas para el Desarrollo.

Reyes, M. (2012). El enfoque Territorial en el Desarrollo Rural; un acercamiento conceptual. En: M. E. Reyes y L. A. López (Coords.), Explorando territorios, una visión desde las Ciencias Sociales, (pp. 209-232). Universidad Autónoma Metropolitana: México.

Reyes, M. y López, A. (2012) (Coords.). Explorando territorios, una visión desde las Ciencias Sociales. Universidad Autónoma Metropolitana: México.

Riffo, L. (2013). 50 años del ILPES: evolución de los marcos conceptuales sobre desarrollo territorial. CEPAL, Santiago, Chile.

Rodríguez, J. \& González, D. (2006). Redistribución de la población y migración interna en Chile: continuidad y cambio según los últimos cuatro censos nacionales de población y vivienda. Revista de geografía Norte Grande, (35), 7-28. https://dx.doi.org/10.4067/S0718-34022006000100002.

Salazar Tetzagüic, Manuel de Jesús. (2009). Multiculturalidad e interculturalidad en el ámbito educativo. Experiencias de países latinoamericanos. Módulo 1: Enfoque teórico. San José, Costa Rica: Instituto Interamericano de Derechos Humanos.

Sabourin, E. (2002). Desenvolvimento rural e abordagem territorial: Conceitos, estratégias, atores. En Eric Sabourin y Olivio Teixeira (eds.), Planejamento e Desenvolvimento dos Territórios Rurais: Conceitos, controvérsias e experiências, (pp.24-41), Brasilia, Embrapa Informação Tecnológica.

Schjetman, A. \& Berdegué, J. (2004). Desarrollo territorial rural. RIMISP, Chile. 
Stefoni, C., Stang, F. \& Riedemann, A. (2016). Educación e interculturalidad en Chile: Un marco para el análisis. Estudios internacionales (Santiago), 48(185), 153-182. https://scielo.conicyt. $\mathrm{cl} / \mathrm{pdf} / \mathrm{rei} / \mathrm{v} 48 \mathrm{n} 185 / \mathrm{art} 08$.pdf.

UNESCO. (2019). Informe de seguimiento de la educación en el mundo. Migración, desplazamiento y educación: construyendo puentes, no muros. Francia: Ediciones UNESCO.

Vaillant, D. (2019). Directivos y comunidades de aprendizaje docente: un campo en construcción. Revista Eletrônica de Educação, 13(1), 87-106.

Valenzuela, J., Bellei, C. \& De los Ríos, D. (2013). Socioeconomic school segregation in a market-oriented educational system. The case of Chile, Journal of Education Policy. doi: 10.1080/02680939.2013.806995. To link to this article: http://dx.doi.org/10.1080/02680939.2 013.806995 .

Villalobos, A., Sanhueza, S. \& Norambuena, C. (2017). Migración y territorialidad: aportes para la construcción de modelos educativos interculturales. Papeles de trabajo - Centro de Estudios Interdisciplinarios en Etnolingüística y Antropología Socio-Cultural, (33), 92-109. Recuperado el 29 de abril de 2019: http://www.scielo.org.ar/scielo.php?script=sci_arttext\&pid=S1852$45082017000100006 \& \operatorname{lng}=\mathrm{es} \& \ln \mathrm{l}=\mathrm{es}$. 
